\title{
The impact of Tetracapsuloides bryosalmonae and Myxobolus cerebralis co- infections on pathology in rainbow trout
}

\author{
Mohamed H. Kotob ${ }^{1,2}$, Bartolomeo Gorgoglione ${ }^{1,3}$, Gokhlesh Kumar ${ }^{1}$, Mahmoud Abdelzaher $^{2}$, Mona Saleh \\ and Mansour El-Matbouli ${ }^{1 *}$
}

\begin{abstract}
Background: Myxozoan parasites pose emerging health issues for wild and farmed salmonid fish. Rainbow trout (Oncorhynchus mykiss) is a particularly susceptible species to Tetracapsuloides bryosalmonae (Malacosporea), the etiological agent of Proliferative Kidney Disease (PKD), and to Myxobolus cerebralis (Myxosporea), the etiological agent of Whirling Disease (WD). The objective of this study was to investigate the impact of myxozoan co-infections on the pathogenesis of PKD and WD in the rainbow trout.
\end{abstract}

Methods: Two groups of rainbow trout (96 fish each) were primarily infected with T. bryosalmonae and triactinomyxons of M. cerebralis; after 30 days half of the fish in each group were co-infected with these parasites vice versa and remaining half was continued as single infection. Mortalities and clinical signs were recorded at different time points. Histopathology and immunohistochemistry were performed to assess the extent of each infection and estimate the parasite burden between groups.

Results: Fish firstly infected with M. cerebralis and co-infected with T. bryosalmonae exhibited exacerbated pathological changes of both parasitic diseases and elicited a higher mortality rate. A higher kidney swelling index (grade 4) appeared together with more severe cartilage destruction and displacement, when compared to the pathological changes in fish upon single infections with T. bryosalmonae or M. cerebralis. Conversely, fish firstly infected with T. bryosalmonae and co-infected with M. cerebralis also exhibited typical pathological changes of both parasitic diseases, but with a lower mortality rate, similar as caused by the single T. bryosalmonae or M. cerebralis infection. WD clinical signs were milder, without skeletal deformities, while kidney swelling index was similar to single infection with T. bryosalmonae (grade 2 to 3 ).

Conclusions: In this study, a co-infection with myxozoan parasites was for the first time successfully achieved in the laboratory under controlled conditions. The impact of co-infections in concurrent myxozoan infections mainly depends on the primary pathogen infecting the host, which could alter the outcomes of the secondary pathogen infection. The primary $M$. cerebralis infection followed by $T$. bryosalmonae had a much more serious impact and elicited a synergistic interaction. Contrasting results were instead seen in rainbow trout primarily infected with T. bryosalmonae and then coinfected with M. cerebralis.

Keywords: Proliferative kidney disease, Whirling disease, Co-infection, Oncorhynchus mykiss, Histopathology

\footnotetext{
* Correspondence: Mansour.El-Matbouli@vetmeduni.ac.at

${ }^{1}$ Clinical Division of Fish Medicine, University of Veterinary Medicine,

Veterinärplatz 1, 1210 Vienna, Austria

Full list of author information is available at the end of the article
} 


\section{Background}

Proliferative Kidney Disease (PKD) and Whirling Disease (WD) are the main issues posed by myxozoan parasites to wild and farmed salmonid fish. PKD is caused by the malacosporean parasite Tetracapsuloides bryosalmonae [1, 2] and currently considered as an emerging disease in Europe and North America [3]. In farmed rainbow trout (Oncorhynchus mykiss) mortality can range from $20 \%$, in uncomplicated cases, up to $95-$ $100 \%$ in outbreaks complicated by secondary infections and stressing conditions [4-7] or when occurring at higher water temperatures [8-10].

PKD was responsible for a long term decrease in brown trout (Salmo trutta) populations in many European countries especially Switzerland [11-14]. Recently, it was linked to the multifactorial etiology of Black Trout Syndrome, decimating autochthonous brown trout in Austria [8]. The life-cycle of T. bryosalmonae includes freshwater bryozoans, Fredericella sultana (Phylactolaemata), as the definitive host and salmonids as the intermediate host $[15,16]$. Kidney and spleen are the main target organs, in which the celozoic sporogonic proliferation (in the lumen of renal tubules and mesonephric ducts) elicits the formation of mature malacospores; but the histozoic extrasporogonic proliferation (in the interstitium) causes a tumor-like chronic lymphoid hyperplasia $[6,17-21]$.

WD is a highly debilitating parasitic disease of salmonid fish, caused by the myxosporean parasite Myxobolus cerebralis [22]. The two-host life-cycle of $M$. cerebralis includes salmonid fish and an oligochaete worm, Tubifex tubifex, releasing triactinomyxon spores infective for salmonids [23]. Myxobolus cerebralis spores proliferate and sporulate within the fish cartilage, as a target site causing severe dysplasia followed by granulomatous reactions and cartilage destruction; thus, WD is characterized by pathognomonic skeletal deformities [24].

Co-infections have serious effects on the host such as changing the host susceptibility to different pathogens, infection duration and altering their pathogenic course $[25,26]$. The interaction occurring between different pathogens during co-infection could be either synergistic, i.e. the presence of one pathogen may enhance subsequent infections and increasing the host susceptibility to other pathogens or antagonistic, i.e. the presence of one pathogen may inhibit and compete with subsequent infections by other pathogens affecting their occurrence and pathogenesis [25-27]. A case study of co-infection by Nucleospora cyclopteri (Microsporidia) and Kudoa islandica (Myxozoa) in farmed lumpfish, Cyclopterus lumpus L., was reported in Norway, with mortality rates up to $65 \%$ [28]. Co-infections with sympatric myxozoans frequently occur in salmonids, showing a variable degree of host competition; including mixed infection of myxozoan species (T. bryosalmonae, Sphaerospora truttae, Chloromyxum schurovi, C. truttae and Myxobolus sp.) which was detected in farmed brown trout in Scotland [29]. Moreover, the initial T. bryosalmonae infection strongly influences the sub-sequential development of $C$. schurovi $[29,30]$.

The fact that PKD and WD will increase their incidence in wild and farmed salmonids due to environmental changes concerns the aquaculture and fishery representatives. PKD is currently considered an emerging disease. New outbreaks were recently described in new geographical areas such as in central Europe in Switzerland [12], Norway [31], Estonia [32], Slovenian rivers [33] and Austria [8]. More recently, a PKD outbreak has been reported in August 2016 in Montana's Yellowstone River in the USA [34], where WD has also been reported to decrease rainbow trout population since the beginning of the twenty-first Century [35-37].

The aim of this study was to investigate the impact of co-infections with the myxozoan parasites $T$. bryosalmonae and M. cerebralis on rainbow trout. The differential host susceptibility was investigated in terms of mortality rate, clinical signs and pathological lesions.

\section{Methods}

\section{Fish maintenance}

Specific pathogen free rainbow trout approximately 2 months post-hatching (mean length $4.02 \pm 0.26 \mathrm{~cm}$, mean weight $0.6 \pm 0.15 \mathrm{~g}$ ) were obtained from a diseasefree certified hatchery (Trout Farm GLÜCK). Fish were acclimatized for 1 week in a $500 \mathrm{l}$ glass tank in a flowthrough system supplied with dechlorinated tap water (approx. $1 \mathrm{l} / \mathrm{m}$; $\mathrm{pH}$ 7.0-7.2; dissolved oxygen 9.0$10.0 \mathrm{mg} / \mathrm{l}$; nitrite $0 \mathrm{mg} / \mathrm{l}$; nitrate $8-10 \mathrm{mg} / \mathrm{l}$; total hardness $179 \mathrm{mg} / \mathrm{l})$ at $16 \pm 1{ }^{\circ} \mathrm{C}$ with adequate aeration provided. The fish room has artificial - as well as day light (12 h light /12 h dark). Feeding rate was adjusted to $1 \%$ BW/day using a commercial pellet (Garant Aqua, Pöchlarn, Austria). Before starting the experiment, 10 fish were randomly sampled during the tank allocation and examined for the presence of any ecto- or endoparasites using light microscopy examinations of mucus smears from skin, gills and gut. Bacterial examinations were also carried out using routine bacteriology from kidney and spleen. The specific presence of T. bryosalmonae or M. cerebralis was tested in the internal organs, including from cranium by using conventional PCR using PKD primers, T.b.18S_F (5'-GGA CAC TGC ATG TGC TGC ATA GT-3') and T.b.18S_R (5'-CCA TGC TAG AAT GTC CAG GCA CT-3') [21] and $M$. cerebralis primers, Tr5-17 (5'-GCC CTA TTA ACT AGT TGG TAG TAT AGA AGC-3'), Tr3-17 (5'-GGC ACA CTA 
CTC CAA CAC TGA ATT TG-3') [38]. All the tested fish were found to be free from ectoparasites, endoparasites and bacteria.

\section{Tetracapsuloides bryosalmonae spores}

Tetracapsuloides bryosalmonae spores were collected from our laboratory infected $F$. sultana colonies [20,39]. Briefly, infected colonies were dissected, mature parasite spore sacs were collected, and a spore suspension was prepared in dechlorinated tap water according to Kumar et al. [20].

\section{Triactinomyxon spores of Myxobolus cerebralis}

Triactinomyxon (TAM) spores were collected through a $20 \mu \mathrm{m}$ mesh sieve from our laboratory infected $T$. tubifex that had been exposed previously to spores of $M$. cerebralis obtained from infected rainbow trout $[24,40]$.

\section{Experimental infection of fish}

The full experimental design is summarized in Fig. 1. After acclimation, rainbow trout were allocated in three groups.

Group 1: 96 rainbow trout were exposed to free $T$. bryosalmonae spores released from 22 mature parasite sacs at $16{ }^{\circ} \mathrm{C}$ according to Kumar et al. [20]. Eight fish were sampled at 1, 7 and 30 days post-exposure (dpe). After 30 days, the remaining 72 fish were divided into two groups (36 fish each) and allocated into separated $60 \mathrm{l}$ aquaria. One group continued as single $T$. bryosalmonae-infected group; the other one was infected with triactinomyxon spores of $M$. cerebralis (2000 TAMs per fish) for $2 \mathrm{~h}$ at $16{ }^{\circ} \mathrm{C}$ as co-infection and continued as $T$. bryosalmonae-then $M$. cerebralis co-infected group ( $T b$-then $M c$ co-infected group). Eight fish were sampled from each group at 60, 90 and 120 dpe.

Group 2: Similar to group 1, 96 rainbow trout were exposed to triactinomyxons (2000 TAMs/fish). After $30 \mathrm{~min}$, two fish were sampled to be examined histologically for the presence of penetrated stages of the triactinomyxon spores of $M$. cerebralis through the epidermis. Eight fish were sampled at 1, 7 and 30 dpe. At 30 days, the remaining fish were equally divided into two groups and allocated into separated $60 \mathrm{l}$ aquaria. One group continued as single $M$. cerebralis-infected group; the other one was infected with free $T$. bryosalmonae spores released from 11 mature parasite sacs as co-infection and continued as $M c$-then $T b$ co-infected group. Eight fish were sampled from each group at 60, 90 and 120 dpe.

Group 3: 60 rainbow trout were allocated in two 601 flow-through aquaria (30 fish/tank) and kept as an uninfected control group. Eight fish were sampled at 1, 7, 30, 60, 90 and 120 dpe.

\section{Fish sampling}

Following experimental exposures, fish were maintained in all tanks under the same conditions such as water parameters, temperature and photoperiod applied as described earlier and monitored three times daily for the appearance of any clinical signs and mortalities were recorded. Fish were sampled at 1, 7, 30, 60, 90,
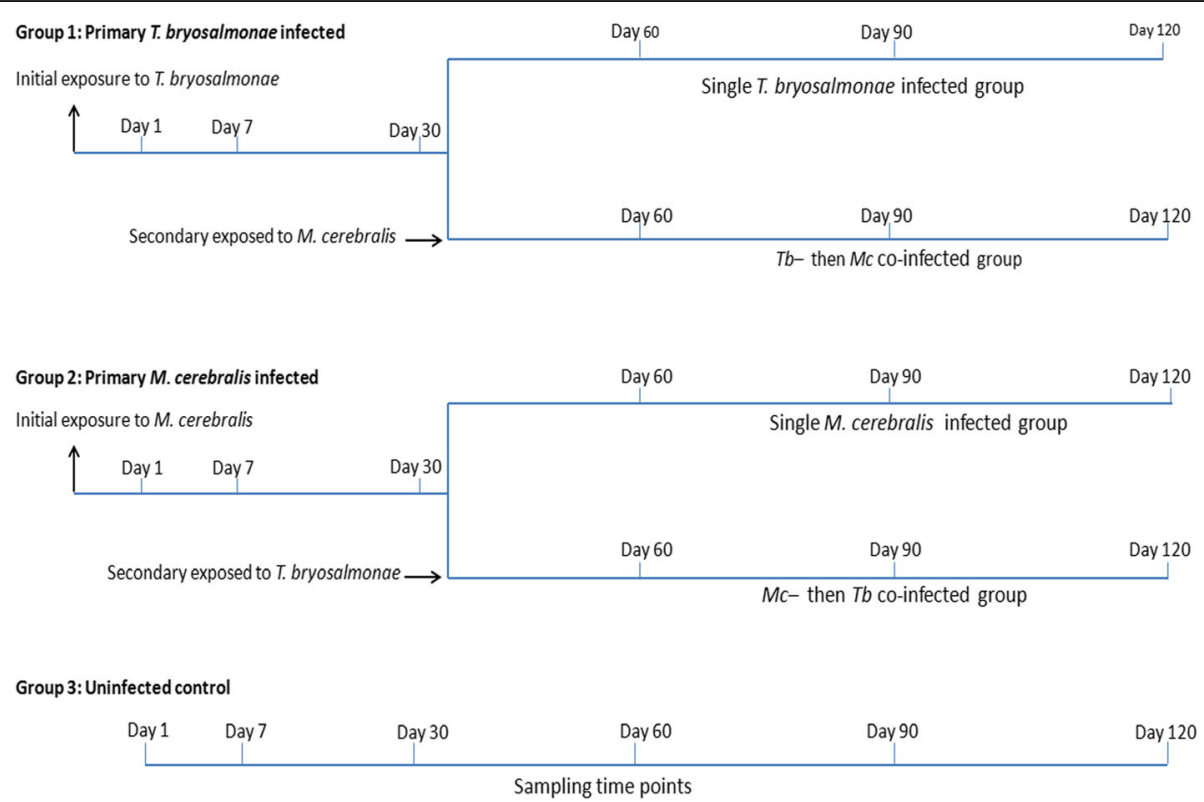

Fig. 1 Schematic experimental design. This design shows three groups: primary T. bryosalmonae-infected, M. cerebralis-infected and uninfected control and different sampling time points 
120 dpe and euthanized using an overdose of tricaine methanesulphonate $(500 \mathrm{mg} / \mathrm{l}, \mathrm{MS}-222$, Sigma-Aldrich, Steinheim, Germany). However, fish showed signs of morbidity and fish that showed skin darkening, lethargy were immediately euthanatized (Endpoint in our animal study proposal).

Total body length (TBL) and total body weight (TBW) were recorded. Samples from posterior kidney, spleen, liver, gills, cranium, vertebral column and brain were divided into 2 portions; one fixed in 10\% neutral buffered formalin for $24 \mathrm{~h}$ and the other preserved in RNA later (Sigma-Aldrich). The kidney swelling index was used to assess the extent of kidney enlargement during PKD, according to Clifton-Hadley et al. [17].

\section{Histology and immunohistochemistry}

Tissue samples were processed for histology, $5 \mu \mathrm{m} \mathrm{sec-}$ tions were stained with hematoxylin and eosin (H\&E) or processed for immunohistochemistry (IHC). The severity of PKD was graded and assessed in $H \& E$ stained sections using the PKD histological assessment, with a grading scale from 1 to 3 according to Peeler et al. [30]. WD lesions were evaluated according to grading scale described by Baldwin et al. [41]. Immunohistochemistry for different tissues at all time points was carried out to assess the presence and burden of $T$. bryosalmonae in the kidneys in single $T$. bryosalmonae infected and in co-infected groups. Tissue sections were incubated with $T$. bryosalmonae monoclonal antibody P01 (1:10 diluted) (Aquatic Diagnostics, Stirling, UK), following the procedures previously described [20]. The antibody-antigen reaction was visualized using a Dako EnVision + System-HRP (AEC) kit (Dako, Carpinteria, USA). Sections were counterstained with hematoxylin and examined for the presence of any parasite stage using an Olympus BX53 microscope. The number of visualized parasites was counted in 10 microscopic fields (at 400× magnifications) in 3 posterior kidney compartments, including the interstitium, blood vessels and lumen of the kidney tubules, as described by Schmidt-Posthaus et al. [42].

\section{Statistical analysis}

Data obtained from the measurement of total body lengths, total body weights and $T$. bryosalmonae parasite numbers were statistically analyzed to detect significant differences between groups (mean \pm SD) by one way ANOVA and LSD using IBM SPSS software version 24 (IBM Corporation). Significant differences between percentages of mortality in single $T$. bryosalmonae, single $M$. cerebralis and co-infected groups were analyzed using two-sample $t$-test (Statistics calculator software). Differences were considered significant when $P<0.05$.

\section{Results}

\section{Clinical signs, gross lesions and mortalities}

During the initial 30 days after primary parasite infections, 2 fish died from single $T b$ infected group and 5 from single $M c$ infected group. After secondary infections the highest mortalities were observed in $\mathrm{Mc}$-then $\mathrm{Tb}$ co-infected group when compared to all infected groups. Data of mortality rates are shown in (Fig. 2).

Fish TBL showed no significant difference between single- and co-infected groups, when compared to the uninfected control group at 1 dpe $\left(F_{(2,21)}=0.435, P=\right.$ $0.653), 7$ dpe $\left(F_{(2,21)}=0.618, P=0.549\right), 30$ dpe $\left(F_{(2,21)}=\right.$ $1.181, P=0.327)$ and 60 dpe $\left(F_{(4,35)}=0.677, P=0.612\right)$. The TBW showed also no significant difference between single- and co-infected groups, when compared to the uninfected control group at 1 dpe $\left(F_{(2,21)}=0.317, P=\right.$ $0.732), 7$ dpe $\left(F_{(2,21)}=0.203, P=0.818\right), 30$ dpe $\left(F_{(2,21)}=\right.$ 1.763, $P=0.196)$ and 60 dpe $\left(F_{(4,35)}=1.417, P=0.249\right)$. The TBL of $M c$-then $T b$ co-infected group was significantly affected at 90 dpe $\left(F_{(4,35)}=4.717, P<0.01\right)$ and 120 dpe $\left(F_{(4,35)}=10.181, P<0.001\right)$. Moreover, the TBW of this group was also significantly affected at 90 dpe $\left(F_{(4,35)}=38.658, P<0.001\right)$ and 120 dpe $\left(F_{(4,35)}=77.736\right.$, $P<0.001)$ when compared to single $T b$, single $M c, T b$ then $M c$ co-infected and uninfected control groups.

Internal PKD lesions were observed after 60 dpe with mild renal hypertrophy and splenomegaly. At 90 dpe, the kidneys swelling became more obvious in the single $\mathrm{Tb}$ infected group (Fig. 3b). There was no remarkable difference in terms of either gross lesions or kidney swelling index (grade 2) between single $T b$ infected and $T b$-then $M c$ co-infected groups at 60 and 90 dpe. However, in $M c$-then $\mathrm{Tb}$ co-infected group, kidneys and spleens were more severely enlarged, up to grade 3 (Fig. 3e).

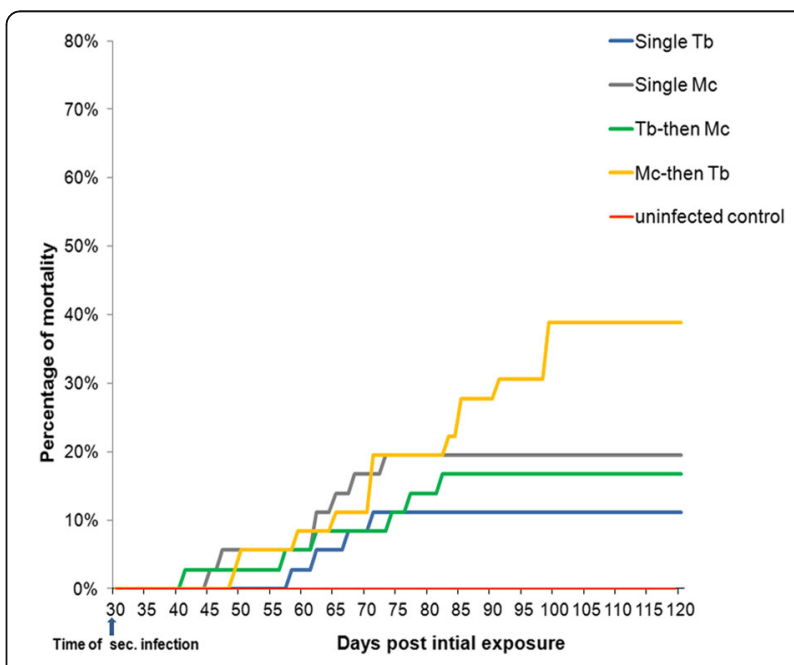

Fig. 2 Mortality percentages of rainbow trout. Mortality was recorded in the all groups after the co-infection onset 

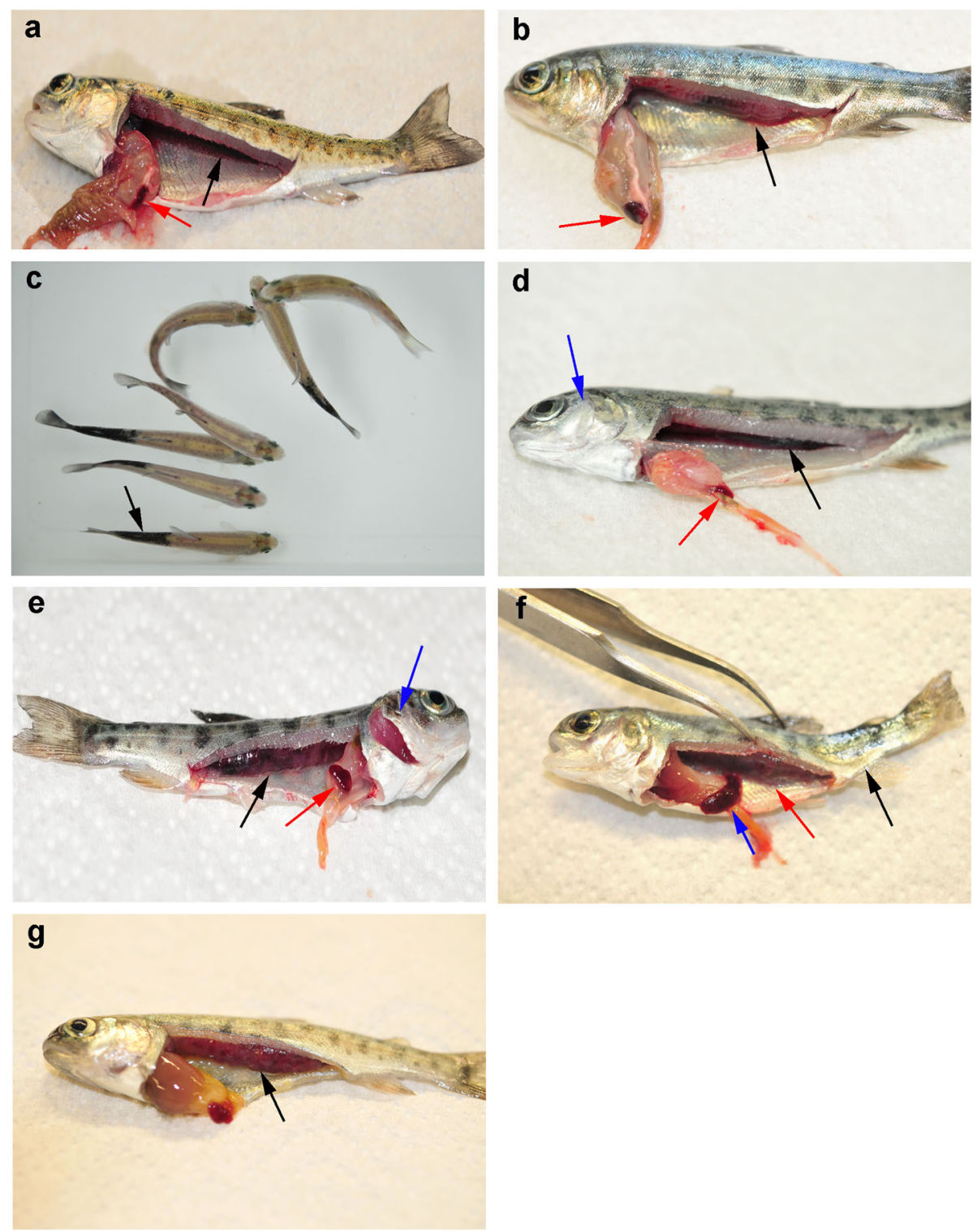

Fig. 3 Comparative clinical appearance of PKD and WD on rainbow trout during single and co-infection. a Uninfected control fish showing normal kidney (black arrow) and spleen (red arrow). b Single Tb infected fish showing enlargement in the kidney (black arrow) and spleen (red arrow) at 90 dpe. c Single Mc infected group at 60 dpe showing some fish exhibited black tail (arrow). d Single Mc infected group at 90 dpe showing deformed gill operculum (blue arrow), normal kidney (black arrow) and normal spleen (red arrow). e Mc-then Tb co-infected fish showing swollen kidney (black arrow) and spleen (red arrow) together with shortening and deformities of gill operculum (blue arrow) at $90 \mathrm{dpe}$ to Mc (60 dpe to Tb). f Mc-then Tb co-infected fish showing bowing of caudal area and skeletal deformities (black arrow) and severely enlarged kidney (red arrow) and spleen (blue arrow), at $120 \mathrm{dpe}$ to Mc (90 dpe to Tb). g Tb-then Mc co-infected fish showing severe enlarged kidney (black arrow), pale liver but no signs of whirling disease were noticed, 120 dpe to Tb (90 dpe to Mc)

At 120 dpe, kidneys and spleens were severely enlarged in all T. bryosalmonae infected groups whereas this enlargement was more and massive in $\mathrm{Mc}$-then $\mathrm{Tb}$ coinfected group, showing a granulomatous-like appearance, scored as grade 4 (Fig. 3f) and ascites was also noticed in moribund fish from this group.

Clinical signs of WD were observed after 40 dpe in $30 \%$ of single $M c$ infected group and in $60 \%$ of $M c$-then
$\mathrm{Tb}$ co-infected group. These signs were in the form of whirling movements with an appearance of slight shortening of gill operculum. At 60 dpe, fish showed black tails (Fig. 3c) and the percentage reached up to $60 \%$ in $M c$-then $\mathrm{Tb}$ co-infected group, when compared to $44 \%$ in single $M c$ infected group.

At 90 and 120 dpe, $M c$-then $T b$ co-infected group showed $100 \%$ whirling movements and $90 \%$ deformities 
in the cranium and caudal area (Fig. 3e, f). Whereas single $M c$ infected group showed $70 \%$ whirling movements and 35\% cranial deformities (Fig. 3d). On the other hand, fish from $T b$-then $M c$ co-infected group showed milder clinical signs of whirling disease. In this group $18 \%$ of fish exhibited whirling movements which appeared after 50 dpe from secondary infection with $M$. cerebralis. Until the end of the experiment (120 dpe), fish of this group did not show any signs of cranial deformities, caudal curvature or black tail (Fig. 3g).

\section{Histopathological assessment}

Tissue samples collected from single $T b$ and $M c$ infected groups at 1 and 7 dpe did not show any evidence of pathological changes. Extrasporogonic stages of T. bryosalmonae were first detected in the kidneys at 30 dpe. Data of renal lesion scores and T. bryosalmonae numbers are summarized in Table 1.

At 60 dpe, the renal interstitial hematopoietic tissue of single $T b$ infected group showed a mild hyperplasia, associated with moderate infiltration of macrophages and lymphocytes (grade 1-2). Interstitial extrasporogonic stages of T. bryosalmonae were surrounded by macrophage cells in a typical rosette appearance (Fig. 4a) and associated with degenerated and necrotic changes of renal tubular epithelia with a presence of hyaline droplets and casts. Some tubules showed the presence of interepithelial parasite stages. No significant differences in the histopathological changes of kidneys of all $T b$ infected groups at 60 dpe. Parasite numbers were higher in $M c$-then $T b$ co-infected group than single $T b$ infected and $T b$-then $M c$ co-infected groups.

At 90 and 120 dpe, up to $50 \%$ of kidney in single $T b$ infected and $T b$-then $M c$ co-infected groups showed lesions of moderate nephritis. Moderate infiltration of chronic inflammatory cells with moderate fibrosis resulted grade 2. Many tubular epithelia showed marked hypercellularity with high mitotic figures at 120 dpe (Fig. 4b).

Whereas in $M c$-then $T b$ co-infected group more than $50 \%$ of kidney showed marked nephritis and fibrosis with infiltration of multinucleated giant cells, macrophages, lymphocytes and epithelioid cells (Fig. 4c, d). A marked peritubular fibrosis was also observed (Fig. 4e).

Liver sections from all $T$. bryosalmonae infected groups showed the presence of multiple foci of inflammatory cellular aggregations containing few parasite stages especially in hepatic sinusoids and sometimes in central veins (Fig. 4f). Spleens showed also presence of moderate numbers of parasite stages in red and white pulp associated with inflammatory cellular infiltration around the zone of infection (Fig. 4g). Spores of T. bryosalmonae were not detected in brain, heart and gill sections either in single $T b$ infected or co-infected groups at all time points.
The penetrating stages of $M$. cerebralis were detected in the epidermis at $30 \mathrm{~min}$ post-exposure and intracellular aggregates of dark stained sporoplasms were seen between the epithelial cells in the dermal layer (Fig. 5a). First observation of developmental stages of $M$. cerebralis was seen in cranium at $30 \mathrm{dpe}$. Cartilage tissues at this period showed a small area of necrosis with few developmental stages of $M$. cerebralis.

At $60 \mathrm{dpe}$, cranial lesions in single $M c$ infected group were grade 3 and characterized by the presence of cartilaginous necrotic foci containing numerous vegetative cells and developmental stages of the parasite (Fig. 5b). The lesions were infiltrated with large numbers of inflammatory cells mainly macrophages and lymphocytes with a beginning of fibrous tissue infiltration. Whereas the cranial lesions were grade 4 in $M c$-then $T b$ coinfected group with severe cartilage destruction involves most of the cranial cartilage with infiltration of inflammatory cells (Fig. 5c).

At 90 dpe, with the progressing of WD, lesions in single $M c$ infected fish became chronic in nature with the presence of numerous mature myxospores and pansporoblasts stages of $M$. cerebralis, grade 3. Infiltration of fibrous tissues and chronic inflammatory cells (macrophages, lymphocytes, plasma cells and fibrocytes) into the affected cartilage were seen (Fig. 5d). The lesions in $M c$-then $T b$ co-infected group were also chronic and still more severe (grade 4) with massive areas of cartilaginous necrosis and displacement. Infiltration of a large amount of fibrotic tissues and chronic inflammatory cells which replaced the affected part of cartilage was seen (Fig. 5e). Gill arch in all M. cerebralis infected groups also showed the presence of mature myxospores associated with inflammatory cell infiltrations and necrosis of cartilaginous tissues.

At 120 dpe, the most characteristic feature was the appearance of multinucleated giant cells in the site of granulomatous inflammation of the affected cartilage (Fig. 5f). Bony tissues were replaced by the formed granulomas leading to destruction of the structural framework and replacement. Fish showed permanent skeletal disfigurations and caudal curvatures which were more obvious at this stage mostly in fish from $M c$-then $T b$ co-infected group. Granulomatous reactions were also observed in the cartilages of vertebral column and most of them were destroyed and containing a large number of myxospores (Fig. 6b). On the contrary, the pathological lesions of WD in $T b$-then $M c$ co-infected group were less and showed minimal infection, grade 1 . And small discrete foci of degenerated cartilage containing few numbers of generative stages of $M$. cerebralis with few infiltrated leukocytes were observed at 60 and 90 dpe to secondary M. cerebralis (Fig. 5g, h). 


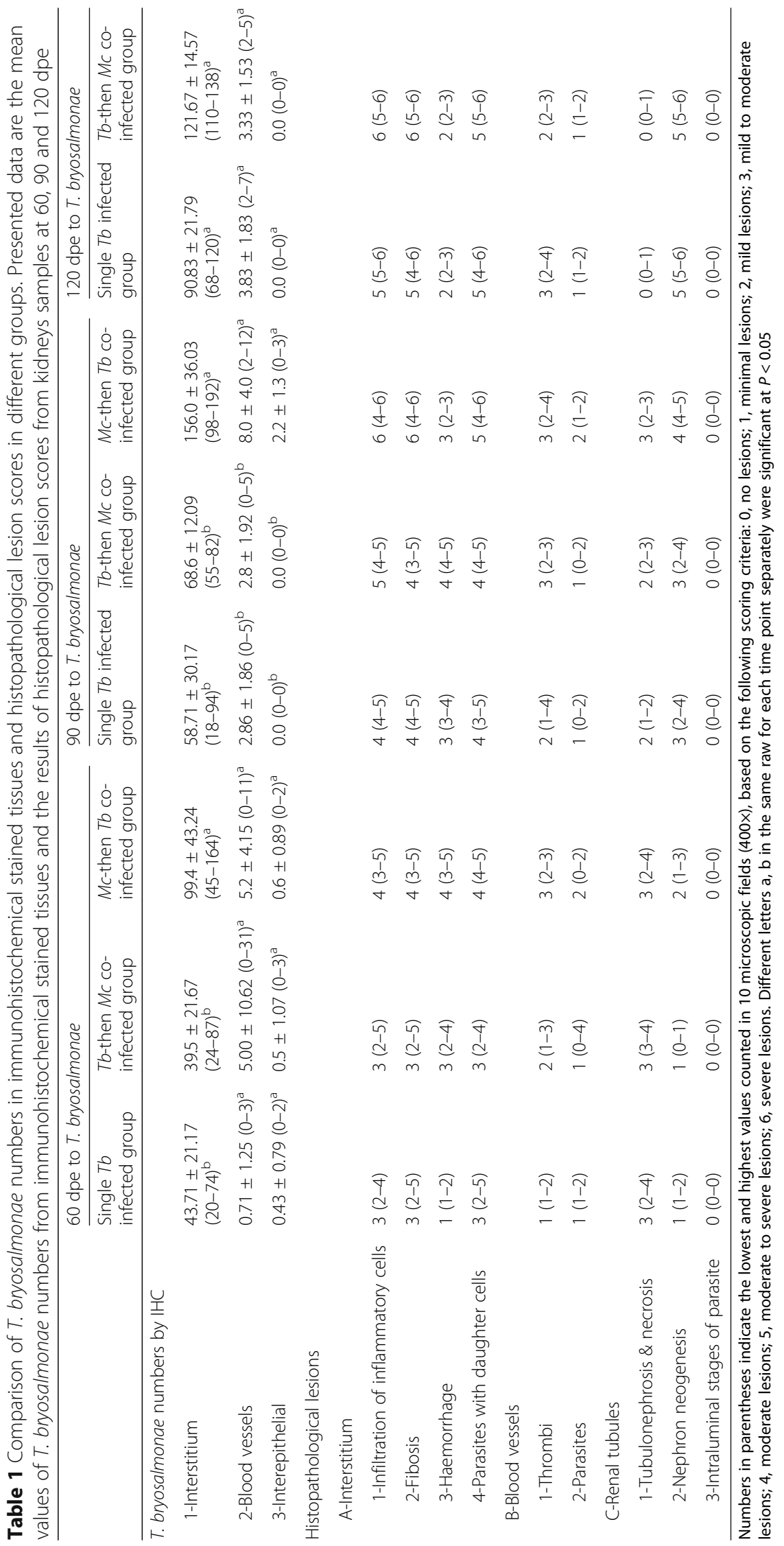



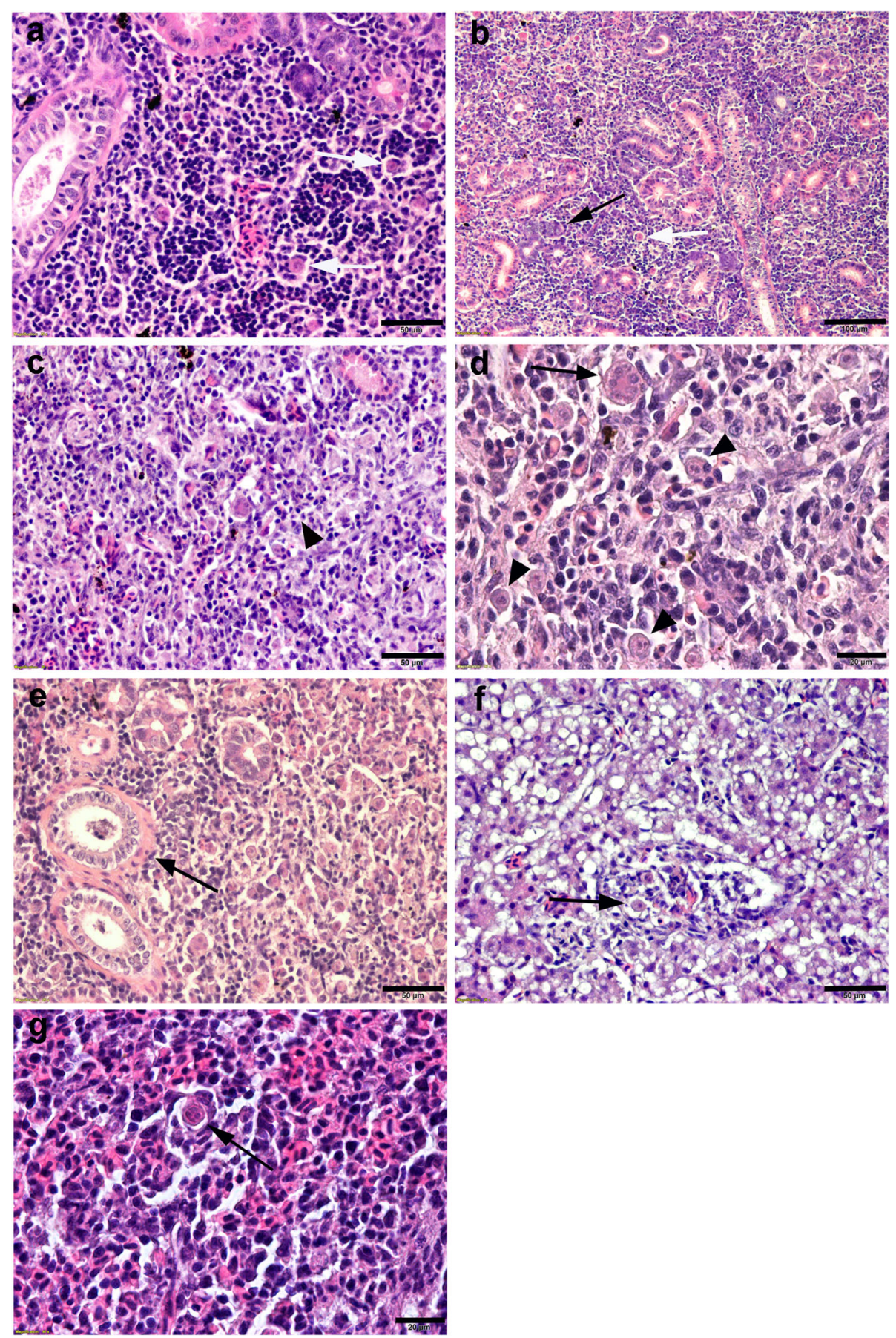

Fig. 4 Comparative histopathology of PKD on rainbow trout during single and co-infection with WD. a Kidney section of single Tb infected group showing interstitial extrasporogonic stages of T. bryosalmonae surrounded by macrophage cells (rosette appearance, arrow) at $60 \mathrm{dpe}$. b Kidney section of single $T b$ infected group at $120 \mathrm{dpe}$, showing pronounced tubular regeneration and tubuloneogenesis with basophilic cytoplasm and increased numbers of mitotic figures (black arrow), note interstitial Tb stages (white arrow). c-e Mc-then Tb co-infected fish, 120 dpe to Mc (90 dpe to $T b$ ), showing $\mathbf{c}$ expanded interstitium due to advanced fibrosis with infiltration of inflammatory cells (arrowhead), $\mathbf{d}$ higher magnification of (c) showing presence of mutinucleated giant cell (arrow) and the parasites (arrowheads) and e peritubular fibrosis (arrow). $\mathbf{f}$ Liver section of single $T b$ infected group at 120 dpe showing presence of inflammatory cellular aggregations containing few parasite stages (arrow). $\mathbf{g}$ Spleen of single $T b$ infected group at 120 dpe showing presence of T. bryosalmonae stages (arrow) in red and white pulp associated with inflammatory cellular infiltration around the zone of infection. H\&E staining. Scale-bars: $\mathbf{a}, 50 \mu \mathrm{m} ; \mathbf{b}, 100 \mu \mathrm{m} ; \mathbf{c}, 50 \mu \mathrm{m} ; \mathbf{d}, 20 \mu \mathrm{m} ; \mathbf{e}, 50 \mu \mathrm{m} ; \mathbf{f}, 50 \mu \mathrm{m} ; \mathbf{g}, 20 \mu \mathrm{m}$ 

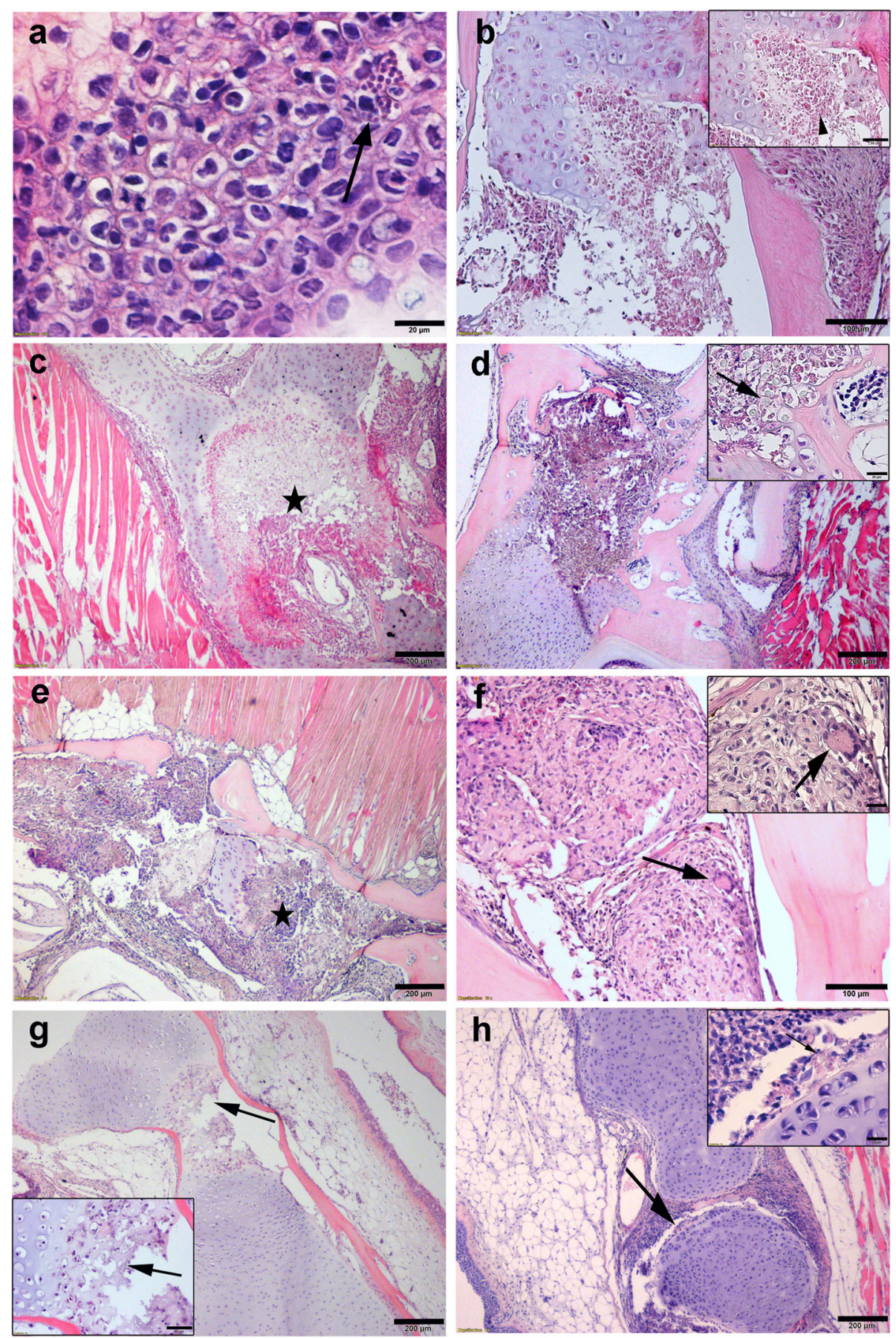

Fig. 5 (See legend on next page.) 
(See figure on previous page.)

Fig. 5 Comparative histopathology of WD on rainbow trout during single and co-infection with PKD. a Epidermis showing numerous intracellular aggregates of dark stained sporoplasms between the epithelial cells 30 min post-exposure to M. cerebralis (arrow). $\mathbf{b}$ Cranium of single Mc infected group, 60 dpe shows presence of cartilaginous necrotic foci containing numerous developmental stages of parasite (inset, arrowhead). c Cranium of Mc-then Tb co-infected group, 60 dpe to Mc (30 dpe to Tb) showing severe cartilage destruction involves most of the cartilage and infiltration of inflammatory tissues (star). $\mathbf{d}$ Single $M c$ infected group at 90 dpe showing presence of numerous mature myxospores in the area of cartilage necrosis (inset, arrow) with infiltration of macrophages and lymphocytes. e Mc-then Tb co-infected group, 90 dpe to Mc (60 dpe to Tb) showing severe destruction of cranial cartilage with displacement (star). $\mathbf{f}$ Affected cranial cartilage of single Mc infected group at 120 dpe showing presence of multinucleated giant cells in the site of granulomatous inflammation (arrow). $\mathbf{g}$ Cranium of Tb-then Mc co-infected group, $90 \mathrm{dpe}$ to Tb (60 dpe to $M c$ ) showing presence of small discrete foci of degenerated cartilage (arrow) and containing few generative stages of $M$. cerebralis with few leukocytes (inset, arrow). h Cranium of Tb-then Mc co-infected group, 120 dpe to Tb (90 dpe to Mc) showing presence of mild cartilagneous degeneration and necrosis with few chronic inflammatory cells surrounding the affected cartilage (arrow) and presence of few mature myxospores (inset, arrow). H\&E staining. Scale-bars: a, $20 \mu \mathrm{m} ; \mathbf{b}, 100 \mu \mathrm{m}$ (inset $50 \mu \mathrm{m}$ ); c, $200 \mu \mathrm{m} ; \mathbf{d}, 200 \mu \mathrm{m}$ (inset $20 \mu \mathrm{m}$ ); e, $200 \mu \mathrm{m} ; \mathbf{f}, 100 \mu \mathrm{m}$ (inset $20 \mu \mathrm{m}$ ); g, $200 \mu \mathrm{m}$ (inset $50 \mu \mathrm{m}$ ); $\mathbf{h}, 200 \mu \mathrm{m}$ (inset $20 \mu \mathrm{m}$ )

\section{Immunohistochemistry}

Table 1 shows numbers of T. bryosalmonae in different kidney compartments of single T. bryosalmonae infected and other co-infected groups. In kidneys, higher numbers of the parasite were observed in the interstitial space and in blood vessels of fish from $M c$-then $T b$ coinfected group when compared to those from single $T b$ infected or $T b$-then $M c$ co-infected groups at 60 and 90 dpe (Fig. 7a-c). Parasite stages were also detected in the gill epithelia of $M c$-then $T b$ co-infected fish at 90 dpe to secondary T. bryosalmonae (Fig. 7d). In liver, at 90 dpe T. bryosalmonae spores were mainly observed in the central veins and hepatic sinusoids in association with macrophages and lymphocytes. The numbers of the parasite were higher in $M c$-then $T b$ co-infected group than single $T b$ infected and $T b$-then $M c$ co-infected groups (Fig. 8a, b). Examination of spleen sections at 90 dpe revealed presence of developmental stages of the parasite in the interstitial hematopoietic tissues which were in higher numbers in $\mathrm{Mc}$-then $\mathrm{Tb}$ co-infected group than other groups (Fig. 8c, d). Moreover, horseshoeshaped multinucleated giant cells were seen in the spleens from $M c$-then $T b$ co-infected group showed a strong positive signal (Fig. 8d). No parasite stages were detected at any time points in heart or brain sections.

\section{Discussion}

Animal diseases studies often focus on single infections with selected host-pathogen models; however, coinfections are common to occur in nature [25, 26, 43]. Co-infection studies are still in their beginning, although limited established models increased demands towards more research in this direction. Multi-parasitic interactions have a strong effect on infection dynamics and play a role in shaping parasite and host populations [43]. The present study describes for the first time a co-infection model with two different myxozoans in rainbow trout, providing novel observations on their impact on mortality rates and pathological lesions. During the experimental period all parameters (water flow rate, temperature and photoperiod applied) were the same for all tanks. Although there were not replicate tanks for the difference exposure regime, we therefore conclude that differences in the mortality rate, body lengths and weights or histopathological lesions were due to the effect of exposure to the parasites in the single and co-infected groups, and not tank effects.
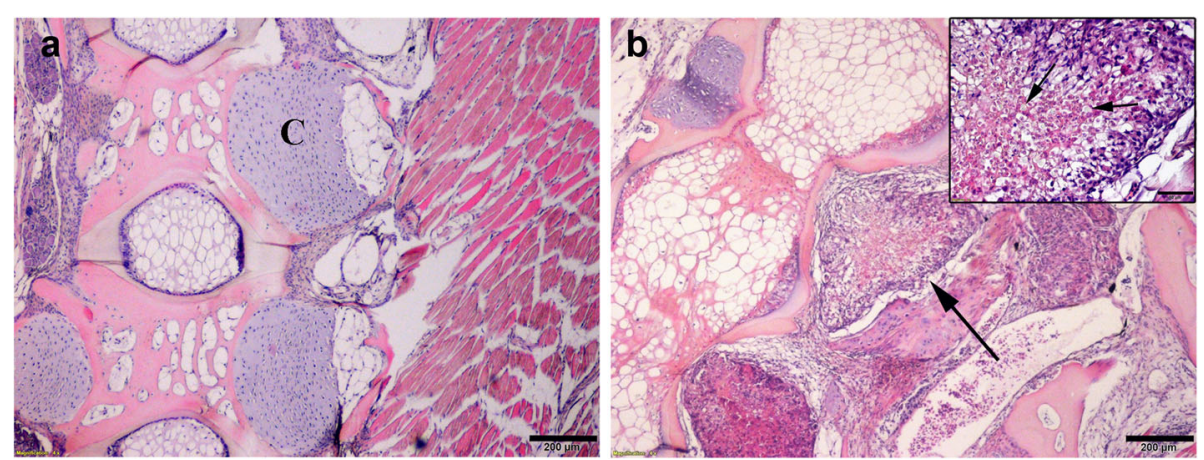

Fig. 6 Histopathology of vertebral column during co-infection. a Uninfected control fish show normal spine with normal cartilage (C). b Spine of Mc-then Tb co-infected group, 120 dpe to Mc (90 dpe to Tb) with severe cartilage necrosis, infiltrating inflammatory cells (arrow) and presence of mature myxospores (inset, arrow). H\&E staining. Scale-bars: a, $200 \mu \mathrm{m} ; \mathbf{b}, 200 \mu \mathrm{m}$ (inset $50 \mu \mathrm{m}$ ) 


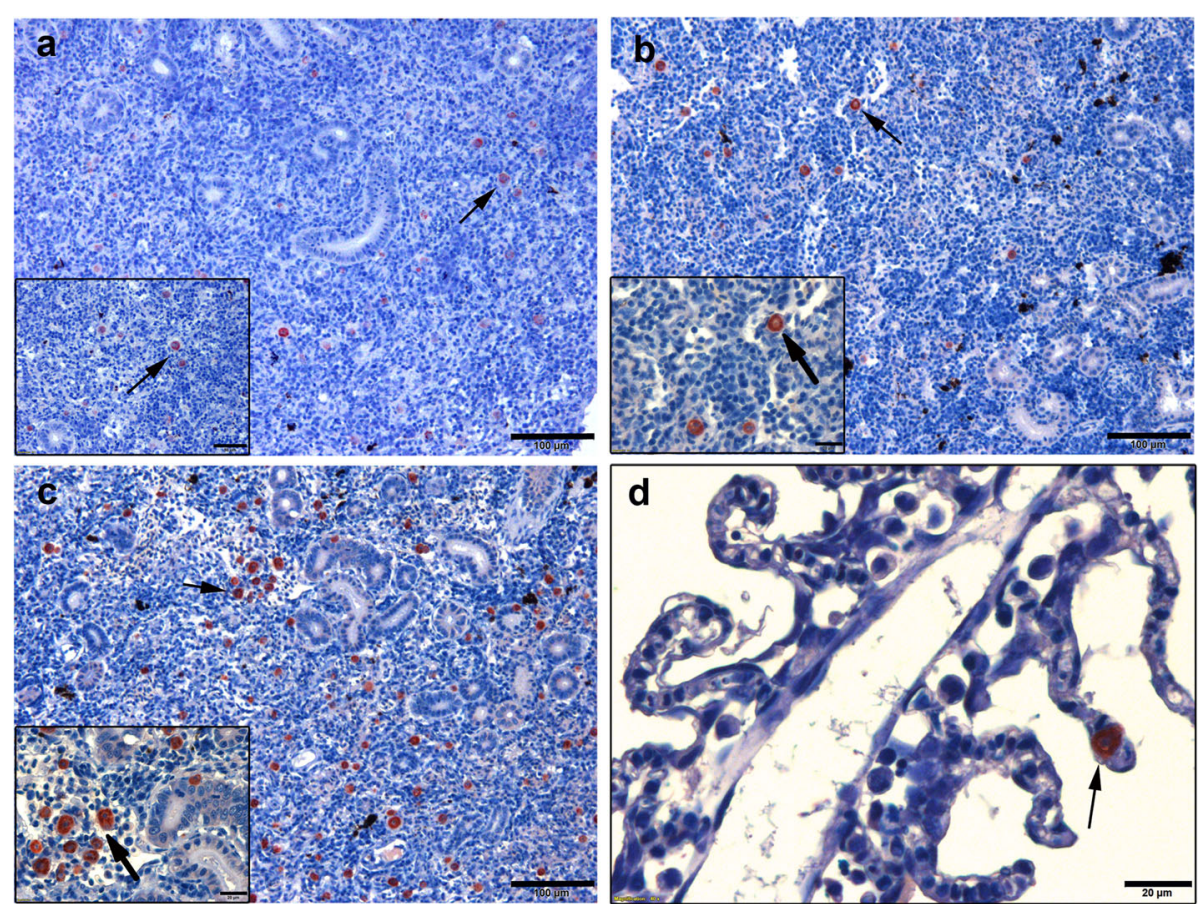

Fig. 7 Comparative immunohistochemistry of PKD on rainbow trout kidney and gills during single and co-infection with WD. $\mathbf{a}$, b Kidney sections of single $T b$ infected and Tb-then Mc co-infected groups respectively at 90 dpe showing moderate numbers of interstitial extrasporogonic stages of Tb (arrow). c, d Mc-then Tb co-infected group, $120 \mathrm{dp}$ initial exposure to Mc (90 dpe to secondary Tb), (c) kidney section showing large number of interstitial extrasporogonic stages of Tb distributed in most of kidney interstitium (arrow), (d) gill section showing presence of one parasite stage of T. bryosalmonae in lamellar epithelium (arrow). Scale-bars: a, $100 \mu \mathrm{m}$ (inset $50 \mu \mathrm{m}$ ); b, $100 \mu \mathrm{m}$ (inset $20 \mu \mathrm{m}$ ); c, $100 \mu \mathrm{m}$ (inset $20 \mu \mathrm{m}$ ); d, $20 \mu \mathrm{m}$

Physical parameters (weights and lengths) were significantly affected at 90 and 120 dpe in $M c$-then $\mathrm{Tb}$ coinfected group compared to single $T b$, single $M c$ and $T b$-then $M c$ co-infected groups. The mortalities were significantly higher in $\mathrm{Mc}$-then $\mathrm{Tb}$ co-infected group when compared to other infected groups. The mortality rates are in accordance with previous records, including that higher mortality occurred during co-infection either with homologous or heterologous or opportunistic secondary pathogens [44, 45]. Gorgoglione et al. [8] also found that highest mortalities $(100 \%)$ were reached when PKD-infected juvenile brown trout were naturally concurrently infected with common ectoparasites, including the ciliated protozoans Ichthyophthirius multifiliis, Chilodonella uncinata and the monogeneans Gyrodactylus derjavini.

We found an exacerbated pathogenesis eliciting more serious clinical signs and pathological lesions of PKD and WD in $M c$-then $T b$ co-infected group, when compared to the single infections with T. bryosalmonae or $M$. cerebralis. This co-infected group showed enlarged kidneys and spleens at 60-120 dpe with a higher kidney swelling index (grade 4), and lesions scores and T. bryosalmonae numbers were significantly higher in the kidneys, spleens and livers as seen by immunohistochemistry. Additionally, this co-infected group also exhibited severe lesions of WD (grade 4) with more severe cartilage destruction and displacement and showed severe skeletal deformities and caudal curvature compared to single $M c$ infected group that showed the lesions but in a lower extent, grade 3. It suggests that severe form of both diseases in co-infected fish may be due to immunosuppression by T. bryosalmonae. PKD is a strong immunosuppressive disease for rainbow trout, thus it increases the susceptibility to opportunistic pathogens upon natural outbreaks $[8,21]$. These results are also in agreement with SchmidtPosthaus et al. [14] describing that the recovery from PKD in brown trout was depending on the presence or absence of concurrent infection with the larvae of the nematode parasite, Raphidascaris acus. Furthermore, the regeneration of the kidney parenchyma was not complete with moderate tubulonephrosis, and chronic renal lesions in the presence of the parasite, whereas, the kidney recovered completely in the absence of the parasite. During the primary infection of rainbow trout with $M$. cerebralis, triactinomyxon-sporoplasms penetrate the epidermis and dermis, then through the peripheral and central nervous system to reach the cartilage during the first 30 days $[24,46]$. Rationally, it seems that the triactinomyxon spores utilize this penetrating way just to escape from the immune response and to more efficiently multiply to higher numbers before reaching 

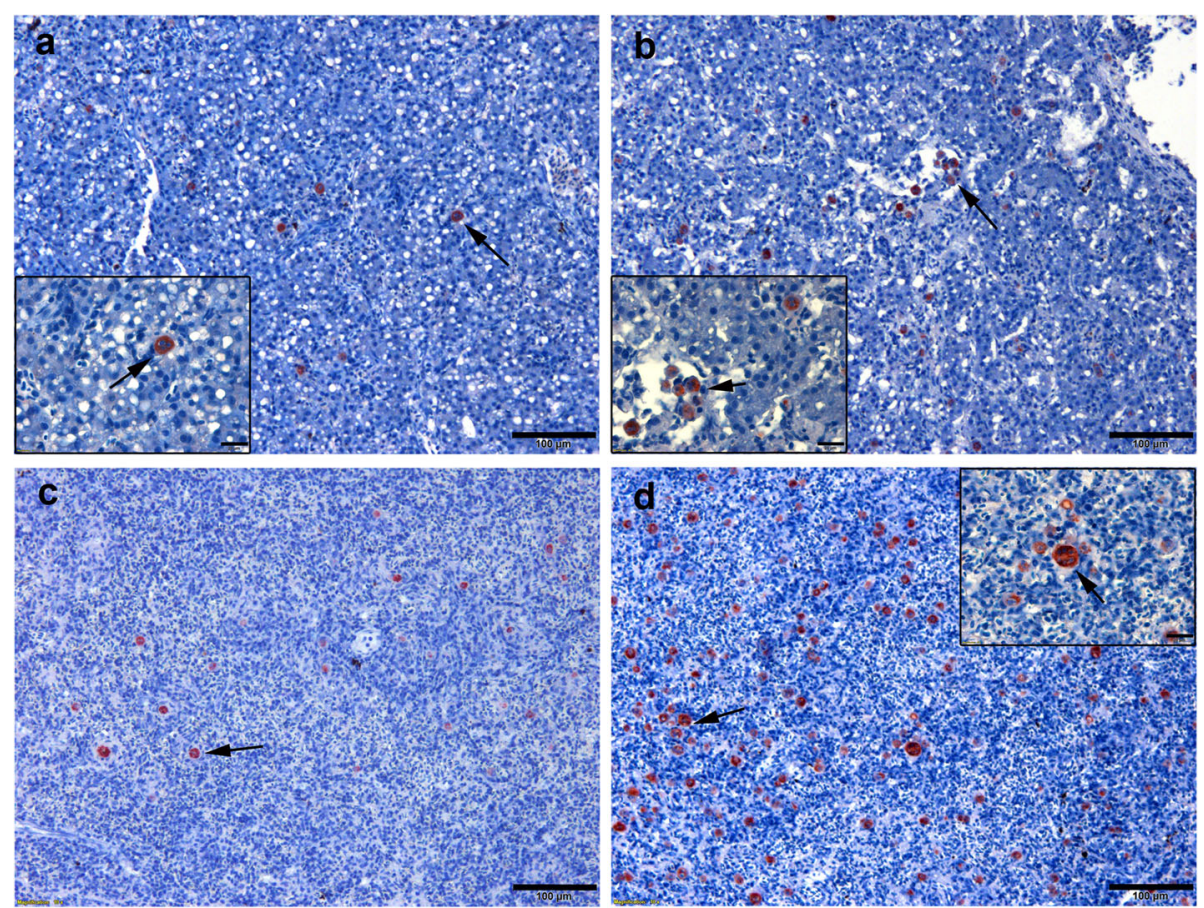

Fig. 8 Comparative immunohistochemistry of PKD on rainbow trout liver and spleen during single and co-infection with WD. a Liver section of single $\mathrm{Tb}$ infected group, 90 dpe showing presence of few parasite stages in hepatic parenchyma (arrow). $\mathbf{b}$ Liver section of Mc-then Tb co-infected group, $120 \mathrm{dp}$ initial exposure to Mc (90 dpe to secondary Tb) showing presence of many parasite stages in hepatic parenchyma and central veins (arrow). c Spleen section of single Tb infected group, 90 dpe showing presence of few parasite stages (arrow). d Spleen section of Mc-then Tb co-infected group, $120 \mathrm{dp}$ initial exposure to Mc (90 dpe to secondary $\mathrm{Tb}$ ) shows presence of many parasite stages in the parenchyma (arrow) associated with horseshoe-shaped multinucleated giant cell, strong positively IHC stained (inset, arrow). Scale-bars: a, $100 \mu \mathrm{m}$ (inset $20 \mu \mathrm{m}$ ); b, $100 \mu \mathrm{m}$ (inset $20 \mu \mathrm{m}$ ); c, $100 \mu \mathrm{m}$; d, $100 \mu \mathrm{m}$ (inset $20 \mu \mathrm{m}$ )

the cartilage as the target site. This is considered one of the reasons that make WD difficult to control [46]. During PKD some key regulatory cytokines are downregulated with a significant decrease in the phagocytic activity of granulocytes, leading to the immunopathological condition [21, 47]. Holland et al. [48] also reported that PKD-infected fish become stressed and exhibit increase susceptibility to secondary infections through stress/cortisol-mediated immune cytokine suppression. Therefore, our explanations of the synergistic interaction occurred in $\mathrm{Mc}$-then $\mathrm{Tb}$ co-infected group, may be due to evasion of the developmental stages of $M$. cerebralis from the immune system and from the strong immunosuppression effect induced by secondary $T$. bryosalmonae. Therefore, fish exhibited the lesions of WD together with the lesions of PKD in an exaggerated form.

Conversely, $T b$-then $M c$ co-infected group exhibited typical pathological changes of both parasitic diseases, but with a lower mortality rate similar as caused by the single $T$. bryosalmonae or $M$. cerebralis infection. The clinical signs and lesions of WD were milder with only slight whirling movements and without skeletal deformities. While kidney swelling index of co-infected fish was similar to single $T$. bryosalmonae infection. We found during this co-infection that secondary infection by $M$. cerebralis resulted in antagonistic interaction and decreased in the fish susceptibility to whirling disease. Anti-T. bryosalmonae antibodies were detected in fish as early as 6 weeks post-exposure [6, 49]. PKD pathogenesis is characterized by a profound $\mathrm{B} /$ antibody response with upregulation of secretory form of IgM and IgT, which positively correlated with $T$. bryosalmonae prevalence $[9,21]$. Anti-T. bryosalmonae monoclonal antibody B4 was found to cross react with sporogonic stage of $M$. cerebralis [50]. The presence of cross-reaction between both parasites could induce a cross-immunity which counteracts with the pathogenesis of secondary WD, suggesting the presence of common antigen in myxozoans $[51,52]$. Hedrick et al. [46] referred to the importance of the first 2-4 dpe to $M$. cerebralis in the development of WD and this support our explanations. Based on the previous studies, we suggest that primary infection with $T$. bryosalmonae may have a role to trigger the innate and adaptive immune response to subsequent infection with $M$. cerebralis. This antagonistic interaction in such case is similar to the negative association between $T$. bryosalmonae and $C$. schurovi during 
mixed infection where infection by one parasite could lower the probability of infection by the second $[29,30]$. Therefore, antagonistic interactions could occur during multi-parasitism as in the results of Brutus et al. [53] and Naus et al. [54] where they found a clear negative association during co-infections with Ascaris and malaria parasite or Schistosoma and Plasmodium, respectively.

No stages of T. bryosalmonae were detected in H\&E stained gill sections of all groups at all time points. However, the immunhistochemical staining showed the presence of some parasite stages in the gill lamellar epithelia of $M c$-then $T b$ co-infected fish. Brain and heart sections from all groups did not exhibit any presence of spores neither in H\&E or IHC stained sections. These results were similar to the results mentioned by Abd-Elfattah et al. [55] who did not find any T. bryosalmonae in brain or intestine sections of chronically infected brown trout. The presence of horseshoe-shaped multinucleated giant cells with strong positive IHC reaction in the spleen at 90 dpe of $M c$-then $T b$ co-infected fish indicated their phagocytic immune role and the immune defence role of the spleen in case of PKD infection to eliminate the parasite. This was in accordance with Morris et al. [56] who found occasionally phagocytes containing degenerated secondary cells of $T$. bryosalmonae via using mAb B4.

\section{Conclusions}

To our knowledge, our study presents for the first time from laboratory infections, the impact of co-infections with myxozoans, $T$. bryosalmonae and $M$. cerebralis, on rainbow trout. The primary $M c$ infection followed by $T b$ had the most serious impact on fish, because of the induced synergistic interaction. The contrary instead occurred in $T b$-then $M c$ co-infection, as signs of WD were diminished and mortality was not affected. Fish showed lesions of PKD as single T. bryosalmonae-infected group. More research would be required to assess the effects of myxozoan infection interactions on the quality of the immunological response differentially elicited in coinfected rainbow trout as a tool toward the development of efficient disease control strategies.

\section{Abbreviations}

Dpe: Days post-exposure; Mc: Myxobolus cerebralis; PKD: Proliferative kidney disease; Tb: Tetracapsuloides bryosalmonae; WD: Whirling disease

\section{Acknowledgments}

We are grateful to all team of the clinical division of Fish Medicine, University of Veterinary Medicine Vienna for their support in the present study. MHK was supported by a PhD scholarship offered for by mission sectors in the ministry of higher education, Egypt.

\section{Funding}

This study was funded in part by the University of Veterinary Medicine and the Austrian Science Fund (FWF) project no. P29294-B25.
Availability of data and materials

All data supporting the conclusions of this article are presented within the article.

\section{Authors' contributions}

BG and MEL designed the study. MHK and BG performed experimental infection and sampled fish. MHK processed the samples for histology. MHK and GK examined the histological sections. MHK and GK performed immunohistochemistry. MHK and GK drafted the manuscript. BG, MA, MS and MEL revised the manuscript. All authors provided comments and corrections on the draft and approved the final manuscript.

\section{Ethics approval}

This study was approved by the institutional ethics committee of the University of Veterinary Medicine Vienna and the national authority, and conducted according to $\$ 26$ of the Austrian Law for Animal Experiments, Tierversuchsgesetz 2012 - TVG 2012 under the permit GZ 68.205/0141-WF/ $\mathrm{V} / 3 \mathrm{~b} / 2015$.

Consent for publication

Not applicable.

\section{Competing interests}

The authors declare that they have no competing interests.

\section{Publisher's Note}

Springer Nature remains neutral with regard to jurisdictional claims in published maps and institutional affiliations.

\section{Author details}

${ }^{1}$ Clinical Division of Fish Medicine, University of Veterinary Medicine, Veterinärplatz 1, 1210 Vienna, Austria. ${ }^{2}$ Department of Pathology, Faculty of Veterinary Medicine, Assiut University, Assiut 71526, Egypt. ${ }^{3}$ Department of Biological Sciences, University of Toledo, Toledo, $\mathrm{OH}$ 43606, USA.

Received: 7 June 2017 Accepted: 28 August 2017

Published online: 25 September 2017

\section{References}

1. Canning EU, Tops S, Curry A, Wood TS, Okamura B. Ecology, development and pathogenicity of Buddenbrockia plumatellae Schröder, 1910 (Myxozoa, Malacosporea) (syn. Tetracapsula bryozoides) and establishment of Tetracapsuloides n. gen. for Tetracapsula bryosalmonae. J Eukaryot Microbiol. 2002:49:280-95.

2. Canning EU, Okamura B. Biodiversity and evolution of the Myxozoa. Adv Parasitol. 2004;56:43-131.

3. Okamura B, Hartikainen H, Schmidt-Posthaus H, Wahli T. Life cycle complexity, environmental change and the emerging status of salmonid proliferative kidney disease. Freshw Biol. 2011;56:735-53.

4. Ferguson HW, Ball HJ. Epidemiological aspects of proliferative kidney disease in rainbow trout, Salmo gairdneri Richardson in Northern Ireland. J Fish Dis. 1979;2:219-25

5. Clifton-Hadley RS, Bucke D, Richards RH. Economic importance of proliferative kidney disease in salmonid fish in England and Wales. Vet Rec. 1986;119:305-6.

6. Hedrick RP, MacConnell E, De Kinkelin P. Proliferative kidney disease of salmonid fish. Annu Rev Fish Dis. 1993;3:277-90.

7. Feist SW, Longshaw M. Phylum Myxozoa. Fish Dis Disord. 2006;1:230-96.

8. Gorgoglione B, Kotob MH, Unfer G, El-Matbouli M. First proliferative kidney disease outbreak in Austria, linking to the aetiology of black trout syndrome threatening autochthonous trout populations. Dis Aquat Org. 2016;119:117-28

9. Bailey C, Segner H, Casanova-Nakayama A, Wahli T. Who needs the hotspot? The effect of temperature on the fish host immune response to Tetracapsuloides bryosalmonae the causative agent of proliferative kidney disease. Fish Shellfish Immunol. 2017;63:424-37.

10. Palikova M, Papezikova I, Markova Z, Navratil S, Mares J, Mares L, et al. Proliferative kidney disease in rainbow trout (Oncorhynchus mykiss) under intensive breeding conditions: pathogenesis and haematological and immune parameters. Vet Parasitol. 2017;238:5--16.

11. Burkhardt-Holm P, Peter A, Segner H. Decline of fish catch in Switzerland. Aquat Sci. 2002;64:36-54 
12. Wahli T, Knuesel R, Bernet D, Segner H, Pugovkin D, Burkhardt-Holm P, et al. Proliferative kidney disease in Switzerland: current state of knowledge. J Fish Dis. 2002;25:491--500.

13. Borsuk ME, Reichert P, Peter A, Schager E, Burkhardt-Holm P. Assessing the decline of brown trout (Salmo trutta) in Swiss rivers using a Bayesian probability network. Ecol Model. 2006;192:224-44.

14. Schmidt-Posthaus H, Steiner P, Müller B, Casanova-Nakayama A. Complex interaction between proliferative kidney disease, water temperature and concurrent nematode infection in brown trout. Dis Aquat Org. 2013;104:23-34.

15. Canning EU, Curry A, Feist SW, Longshaw M, Okamura BA. New class and order of myxozoans to accommodate parasites of bryozoans with ultrastructural observations on Tetracapsula bryosalmonae (PKX organism). J Eukaryot Microbiol. 2000:4:456-68.

16. Okamura B, Wood TS. Bryozoans as hosts for Tetracapsula bryosalmonae, the PKX organism. J Fish Dis. 2002;25:469-75.

17. Clifton-Hadley RS, Bucke D, Richards RHA. Study of the sequential clinical and pathological changes during proliferative kidney disease in rainbow trout, Salmo gairdneri Richardson. J Fish Dis. 1987;10:335-52.

18. Morris DJ, Adams A. Transmission of Tetracapsuloides bryosalmonae (Myxozoa: Malacosporea), the causative organism of salmonid proliferative kidney disease, to the freshwater bryozoan Fredericella sultana. Parasitology. 2006;133:701-9.

19. Grabner DS, El-Matbouli M. Transmission of Tetracapsuloides bryosalmonae (Myxozoa: Malacosporea) to Fredericella sultana (Bryozoa: Phylactolaemata) by various fish species. Dis Aquat Org. 2008;79:133-9.

20. Kumar G, Abd-Elfattah A, Saleh M, El-Matbouli M. Fate of Tetracapsuloides bryosalmonae (Myxozoa) after infection of brown trout (Salmo trutta) and rainbow trout (Oncorhynchus mykiss). Dis Aquat Org. 2013;107:9-18.

21. Gorgoglione B, Wang T, Secombes CJ, Holland JW. Immune gene expression profiling of proliferative kidney disease in rainbow trout Oncorhynchus mykiss reveals a dominance of anti-inflammatory, antibody and $T$ helper cell-like activities. Vet Res. 2013;44:55.

22. Wolf K, Markiw ME. Biology contravenes taxonomy in the Myxozoa: new discoveries show alternation of invertebrate and vertebrate hosts. Science. 1984;225:1449-52.

23. El-Matbouli M, Hoffmann RW. Experimental transmission of two Myxobolus spp. developing bisporogeny via tubificid worms. Parasitol Res. 1989;75:461-4

24. El-Matbouli M, Hoffmann RW, Mandok C. Light and electron microscopic observations on the route of the triactinomyxon-sporoplasm of Myxobolus cerebralis from epidermis into rainbow trout cartilage. J Fish Biol. 1995;46:919-35.

25. Cox FEG. Concomitant infections, parasites and immune responses. Parasitology. 2001;122:S23-38

26. Kotob MH, Menanteau-Ledouble S, Kumar G, Abdelzaher M, El-Matbouli M. The impact of co-infections on fish: a review. Vet Res. 2016;47:98.

27. Bradley JE, Jackson JA. Measuring immune system variation to help understand host-pathogen community dynamics. Parasitology. 2008;135:807-23.

28. Alarcón M, Thoen E, Poppe TT, Bornø G, Mohammad SN, Hansen H. Coinfection of Nucleospora cyclopteri (Microsporidia) and Kudoa islandica (Myxozoa) in farmed lumpfish, Cyclopterus lumpus L., in Norway: a case report. J Fish Dis. 2016;39:411-8.

29. Holzer AS, Sommerville C, Wootten R. Molecular studies on the seasonal occurrence and development of five myxozoans in farmed Salmo trutta $\mathrm{L}$. Parasitology. 2006;132:93-205.

30. Peeler EJ, Feist SW, Longshaw M, Thrush MA, St-Hilaire S. An assessment of the variation in the prevalence of renal myxosporidiosis and hepatitis in wild brown trout, Salmo trutta L., within and between rivers in south-west England. J Fish Dis. 2008;31:719-28.

31. Mo TA, Jørgensen AA. Survey of the distribution of the PKD-parasite Tetracapsuloides bryosalmonae (Cnidaria: Myxozoa: Malacosporea) in salmonids in Norwegian rivers - additional information gleaned from formerly collected fish. J Fish Dis. 2017;40:621-7.

32. Dash M, Vasemägi A. Proliferative kidney disease (PKD) agent Tetracapsuloides bryosalmonae in brown trout populations in Estonia. Dis Aquat Org 2014;109:139-48.

33. Jenčič V, Zajc U, Kušar D, Ocepek M, Pate M. A survey on Tetracapsuloides bryosalmonae infections in Slovene fresh waters. J Fish Dis. 2014;37:711-7.

34. Fish M. Wildlife \& Parks: Yellowstone River fish kill fact sheet accessed Sept. In: 22; 2016. http://fwp.mt.gov/news/newsReleases/headlines/nr_4278.html.

35. Koel TM, Bigelow PE, Doepke PD, Ertel BD, Mahony DL. Nonnative lake trout result in Yellowstone cutthroat trout decline and impacts to bears and anglers. Fisheries. 2005;30:10-9.
36. Koel TM, Mahony DL, Kinnan KL, Rasmussen C, Hudson CJ, Murcia S, Kerans BL. Myxobolus cerebralis in native cutthroat trout of the Yellowstone Lake ecosystem. J Aquat Anim Health. 2006;18:157-75.

37. Murcia S, Kerans BL, MacConnell E, Koel TM. Myxobolus cerebralis infection patterns in Yellowstone cutthroat trout after natural exposure. Dis Aquat Org. 2006;71:191-99.

38. Andree KB, MacConnell E, Hedrick RPA. Nested polymerase chain reaction for the detection of genomic DNA of Myxobolus cerebralis in rainbow trout Oncorhynchus mykiss. Dis Aquat Org. 1998;34:145-54.

39. Kumar G, Abd-Elfattah A, Soliman H, El-Matbouli M. Establishment of medium for laboratory cultivation and maintenance of Fredericella sultana for in vivo experiments with Tetracapsuloides bryosalmonae (Myxozoa). J Fish Dis. 2013:36:81-8.

40. Hedrick RP, McDowell TS, Gay M, Marty GD, Georgiadis MP, MacConnell E. Comparative susceptibility of rainbow trout Oncorhynchus mykiss and brown trout Salmo trutta to Myxobolus cerebralis, the cause of salmonid whirling disease. Dis Aquat Org. 1999;37:173-83.

41. Baldwin TJ, Vincent ER, Silflow RM, Stanek D. Myxobolus cerebralis infection in rainbow trout (Oncorhynchus mykiss) and brown trout (Salmo trutta) exposed under natural stream conditions. J Vet Diagn Investig. 2000;12:312-21.

42. Schmidt-Posthaus H, Bettge K, Forster U, Segner H, Wahli T. Kidney pathology and parasite intensity in rainbow trout Oncorhynchus mykiss surviving proliferative kidney disease: time course and influence of temperature. Dis Aquat Org. 2012;97:207-18.

43. Vaumourin E. Vourc'h G, Gasqui P, Vayssier-Taussat M. The importance of multiparasitism: examining the consequences of co-infections for human and animal health. Parasit Vectors. 2015;8:545.

44. Dong HT, Nguyen W, Phiwsaiya K, Gangnonngiw W, Withyachumnarnkul B, Rodkhum C, et al. Concurrent infections of Flavobacterium columnare and Edwardsiella ictaluri in striped catfish, Pangasianodon hypophthalmus in Thailand. Aquaculture. 2015:448:142-50.

45. DH X, Shoemaker CA, Klesius PH. Evaluation of the link between gyrodactylosis and streptococcosis of Nile tilapia, Oreochromis niloticus (L.). J Fish Dis. 2007;30:233-8

46. Hedrick RP, Adkinson MA, MacConell E. Whirling disease: re-emergence among wild trout. Immunol Rev. 1998;166:365-76.

47. Chilmonczyk S, Monge D, De Kinkelin P. Proliferative kidney disease: cellular aspects of the rainbow trout, Oncorhynchus mykiss (Walbaum), response to parasitic infection. J Fish Dis. 2002;25:217-26.

48. Holland JW, Gould CRW, Jones CS, Noble LR, Secombes CJ. The expression of immune-regulatory genes in rainbow trout, Oncorhynchus mykiss, during a natural outbreak of proliferative kidney disease (PKD). Parasitology. 2003;126:S95-S102.

49. Hedrick RP, Monge D, Kazanji M, Marin M, De Kinkelin P. Recent development with proliferative kidney disease. In: Kimura T, editor. Proceedings of the OJ international symposium on salmonid diseases. Sapporo: Hokkaido University press; 1991. p. 276-82.

50. Morris DJ, El-Matbouli M, Adams A. Extensive release of an antigen associated with the sporogonic stages of Myxobolus cerebralis (Myxozoa: Myxosporea) is detected by a heterologous antibody raised to Tetracapsuloides bryosalmonae (Myxozoa: Malacosporea). Folia Parasitol. 2004;51:215-20.

51. Marin de Mateo M, McGeorge J, Morris D, Kent ML. Comparative studies of PKX and Sphaerospora spp. from salmonids using lectin and monoclonal antibody staining techniques. J Fish Dis. 1996;19:55--63.

52. Morris DJ, Molnar K, Longshaw M, Adams A. Immunostaining of spores and plasmodia of disparate myxozoan genera with comments on the properties of the sporular mucus envelope. Parasitology. 2006;132:781-90.

53. Brutus L, Watier L, Briand V, Hanitrasoamampionona V, Razanatsoarilala $H$, Cot M. Parasitic co-infections: does Ascaris lumbricoides protect against Plasmodium falciparum infection? Am J Trop Med Hyg. 2006;75:194-8.

54. Naus CW, Jones FM, Satti MZ, Joseph S, Riley EM, Kimani G, et al. Serological responses among individuals in areas where both schistosomiasis and malaria are endemic: cross-reactivity between Schistosoma mansoni and Plasmodium falciparum. J Infect Dis. 2003;187:1272-82.

55. Abd-Elfattah A, Kumar G, Soliman H, El-Matbouli M. Persistence of Tetracapsuloides bryosalmonae (Myxozoa) in chronically infected brown trout Salmo trutta. Dis Aquat Org. 2014;111:41-9.

56. Morris DJ, Adams A, Richards RH. Studies of the PKX parasite in rainbow trout via immunohistochemistry and immunogold electron microscopy. Aquat Anim Health. 1997:9:265-72. 